\title{
Urgent care costs of uncontrolled asthma in Canada, 2004
}

\author{
Soo Jin Seung $\mathrm{HBSc}^{1}$, Nicole Mittmann MSc $\mathrm{PhD}^{1,2}$
}

\begin{abstract}
SJ Seung, N Mittmann. Urgent care costs of uncontrolled asthma in Canada, 2004. Can Respir J 2005;12(8):435-436.

It has been more than a decade since Krahn evaluated the direct and indirect costs of asthma in Canada. Asthma is often uncontrolled and the cost of providing urgent care has not been determined. Hospitalizations, unscheduled physician visits, emergency department visits, drug treatments and ambulance rides are resources used by the uncontrolled asthmatic population, resulting in $\$ 162$ million in costs annually. Improved control of asthma could decrease these costs.
\end{abstract}

\section{Les coûts des soins d'urgence de l'asthme au Canada en 2004}

Il y a plus de dix ans que Krahn a évalué les coûts directs et indirects de l'asthme au Canada. L'asthme est souvent non contrôlé, et le coût des soins d'urgence n'est pas établi. L'hospitalisation, les consultations non prévues chez le médecin, les consultations à l'urgence, les traitements médicamenteux et les déplacements en ambulance sont des ressources utilisées par la population d'asthmatiques non contrôlés, qui entrânent des coûts annuels de 162 millions de dollars. Un meilleur contrôle de l'asthme permettrait de réduire ces coûts.

Key Words: Burden of illness; Costs; Uncontrolled asthma

A sthmatic patients experience variable airflow limitation as well as hyper-responsiveness of airways to endogenous and exogenous stimuli (1). Based on the 1999 Canadian Asthma Consensus Group's definition of acceptable asthma control parameters, a recent survey of 1001 asthmatic patients reported that asthma was uncontrolled $57 \%$ of the time (2). Signs of uncontrolled asthma can also include a recent hospital admission or an emergency department (ED) visit (1). Although the cost of asthma has been estimated in several published Canadian studies (3-6), the objective of the present study was to determine the use of urgent care resources and the annual costs of the uncontrolled asthmatic population in Canada.

\section{METHODS}

\section{The uncontrolled asthmatic population}

In $1998 / 1999$, the number of asthmatic patients in Canada was $2,389,085$, or $8.5 \%$ of the population aged four years or older (7). If $57 \%$ of asthmatic patients are uncontrolled (2), this would result in a population of 1,350,871 individuals with uncontrolled asthma.

\section{Costs}

All costs are given in 2004 Canadian dollars (Table 1). Earlier costs were inflated to 2004 via the consumer price index for Canada (8). The unit cost of an ED visit (\$240.96) was determined by inflating Krahn et al's 1990 estimate of $\$ 120$ (3) and adding the Ontario ED physician consultation fee of $\$ 80.75$ (9). For the unit cost of an ambulance ride (\$195), it was assumed that the ED physician would assess that the ambulatory transport was medically necessary for uncontrolled asthmatic patients, as per the guidelines of the Ontario Ministry of Health and Long-Term Care (10). The unit cost of a hospital day (\$804.32) was determined based on Ontario Case Costing Initiative data from the 2001/2002 dataset (11) using the Ninth International Classification of Diseases (12) code 493 for asthma. A total of 1118 cases yielded an average total cost of $\$ 2,128.90$ for a length of stay of 2.8 days. For the unit cost of an unscheduled family physician visit $(\$ 27.85)$, the Ontario Ministry of Health and Long-Term Care billing code A888 was used (9). Only the $\$ 4.64$ drug acquisition cost of a salbutamol $100 \mu \mathrm{g} / \mathrm{metered}$ dose inhaler for 200 doses (13) was considered in the present analysis (pharmacy markup and dispensing fees were excluded).

\section{Resource utilization}

It was assumed that all ED visits, hospitalizations and unscheduled family physician visits of asthmatic patients in Canada were due to their asthma being uncontrolled. The 2001/2002 National Ambulatory Care Reporting System (14) indicated a total of 80,595 ED visits due to asthma (Table 1). Krahn et al (3) assumed that $5 \%$ of asthma-related ED visits in Canada would require an ambulance ride and this assumption was also used in the present study, giving a total of 4030 ambulance rides. The rate of hospitalization due to asthma in Canada (143 per 100,000) (15) was multiplied by Statistics Canada's January 1, 2004, postcensal estimate of the national population $(31,788,635)$ to yield 45,458 hospitalizations and 127,282 hospital days (2.8 days per hospitalization). The number of unscheduled physician visits was based on $88 \%$ of uncontrolled asthmatic patients making unscheduled physician visits (2) and, therefore, almost 1.2 million unscheduled (family) physician visits were made. It was assumed that all of the uncontrolled asthmatic patients in Canada required at least one salbutamol inhaler over one year.

\section{RESULTS}

Table 1 summarizes the unit costs that were multiplied by the resource utilization rates to obtain an overall total of $\$ 162$ million,

${ }^{1}$ HOPE Research Centre, Division of Clinical Pharmacology, Department of Medicine, Sunnybrook and Women's College Health Sciences Centre; ${ }^{2}$ Department of Pharmacology, University of Toronto, Toronto, Ontario

Correspondence and reprints: Soo Jin Seung, HOPE Research Centre, Sunnybrook and Women's College Health Sciences Centre,

2075 Bayview Avenue, Room E240, Toronto, Ontario M4N 3M5. Telephone 416-480-4851, fax 416-480-6025, e-mail soojin.seung@sw.ca 
TABLE 1

Urgent care costs (2004 CDN\$) of uncontrolled asthma

\begin{tabular}{lrrr}
\hline Cost variables & Unit cost (\$) & Utilization & Total cost (\$) \\
\hline Hospital days & 804.32 & 127,282 & $102,375,458$ \\
Unscheduled family physician visits & 27.85 & $1,188,766$ & $33,107,133$ \\
Emergency department visits & 240.96 & 80,595 & $19,420,171$ \\
Short-acting beta-2-agonist salbutamol & 4.64 & $1,350,871$ & $6,268,041$ \\
Ambulance rides & 195.00 & 4,030 & 785,850 \\
Overall total & - & - & $161,956,653$ \\
\hline
\end{tabular}

the amount that is spent annually for treating uncontrolled asthma in Canada. Hospitalizations due to uncontrolled asthma were the largest cost contributor (63\%), followed by unscheduled family physician visits (20\%), ED visits (12\%), salbutamol treatment $(4 \%)$ and ambulance rides $(0.5 \%)$.

\section{DISCUSSION}

The present cost-assessment study is the first attempt at calculating the urgent care cost of uncontrolled asthmatic patients in Canada. Previously, Krahn et al (3) calculated that the direct overall costs (in 1990) of asthma totalled \$306 million and consisted of nine different cost components. Asthma drugs were the largest cost component (\$124 million) and consisted of beta-2-adrenergic agonists, ipratropium bromide, theophylline preparations, sodium cromoglycate and inhaled corticosteroids. Because this analysis determined only the urgent care costs of uncontrolled asthma, the bronchodilator salbutamol was the only asthma drug considered for the symptomatic relief of exacerbations. The costs of inhaled corticosteroids would be captured under standard asthma care.

The use of certain assumptions in the absence of specific data limited the present study. For example, ED visits for asthma

\section{REFERENCES}

1. Boulet LP, Becker A, Berube D, Beveridge R, Ernst P. Canadian Asthma Consensus Report, 1999. Canadian Asthma Consensus Group. CMAJ 1999;161(Suppl 11):S1-61.

2. GlaxoWellcome. Asthma in Canada: A Landmark Survey, 2000. $<$ www.asthmaincanada.com/manage/execsumm_en.pdf $>$ (Version current at May 3, 2005).

3. Krahn MD, Berka C, Langlois P, Detsky AS. Direct and indirect costs of asthma in Canada, 1990. CMAJ 1996;154:821-31.

4. Ungar WJ, Coyte PC; Pharmacy Medication Monitoring Program Advisory Board. Prospective study of the patient-level cost of asthma care in children. Pediatr Pulmonol 2001;32:101-8.

5. Awadh Behbehani N, Grunfeld A, FitzGerald JM. Health care costs associated with acute asthma: A prospective economic analysis. Can Respir J 1999;6:521-5.

6. Ungar WJ, Coyte PC, Chapman KR, MacKeigan L. The patient level cost of asthma in adults in south central Ontario. Pharmacy Medication Monitoring Program Advisory Board. Can Respir J 1998;5:463-71.

7. Statistics Canada. Asthma, by sex, household population aged 4 and over, Canada and provinces, 1994/95-1998/99. Health Indicators, April 2001. Catalogue no 82-221-XIE. <www.statcan.ca/english/freepub/82-221-XIE/ 00401/tables/pdftables/P1252.pdf> (Version current at May 3, 2005).

8. Bank of Canada. <www.bankofcanada.ca/en/inflation_calc.htm> (Version current at May 3, 2005).
TABLE 2

Different utilization data on urgent asthma care for asthmatic patients in Canada $(n=2,389,085)$

\begin{tabular}{lccc}
\hline $\begin{array}{l}\text { Urgent care } \\
\text { component }\end{array}$ & $\begin{array}{c}\mathbf{2 0 0 4} \\
\text { utilization, \% (n) }\end{array}$ & $\begin{array}{c}\mathbf{2 0 0 0} \\
\text { utilization, \% (n) }\end{array}$ & $\begin{array}{c}\mathbf{1 9 9 6 / 1 9 9 7} \\
\text { utilization, \% (n) }\end{array}$ \\
\hline Hospital days & 143 per 100,000 & 7 & 5.3 \\
& $(127,282)$ & $(468,261)$ & $(354,542)$ \\
Unscheduled family & 50 & 35 & 43 \\
physician visits & $(1,188,766)$ & $(836,180)$ & $(1,027,307)$ \\
Emergency & 3.4 & 28 & 18 \\
department visits & $(80,595)$ & $(668,944)$ & $(430,035)$ \\
\hline
\end{tabular}

in 2001/2002 were used and assumed to be the same for 2004, as well as fees and costs from one province (Ontario) to represent all of Canada.

Moreover, another limitation of the present study is that the results could be an underestimation of the actual costs of urgent care for uncontrolled asthmatic patients. For example, based on the 2001/2002 National Ambulatory Care Reporting System (14), there were 80,595 ED visits. However, Health Canada's report on respiratory diseases in Canada (15) cited the 1996/1997 National Population Health Survey Asthma Supplement, which found that $18 \%$ of active asthmatic patients had been to the ER at least once in the previous year, compared with 28\% from the GlaxoWellcome survey of 1001 asthmatic patients (2). Table 2 outlines other utilization data for three urgent care components.

Future studies will include the following: clinical opinion leaders updating the current control definitions, because many asthmatic patients considered to be controlled may actually be uncontrolled (16); identifying specific outcomes associated with urgent care resources via a retrospective chart review or extensive linkage with national health care databases; and a prospective patient registry of uncontrolled asthmatic patients.

9. Ontario Ministry of Health and Long-Term Care. Consultations and Visits. <www.health.gov.on.ca/english/ providers/program/ohip/sob/ physserv/a_consul.pdf> (Version current at May 3, 2005).

10. Ontario Ministry of Health and Long-Term Care. Ambulance Services. <www.infogo.gov.on.ca/paceweb/owa/intersrv_en.disp_service_ det?IN_SERVICE_ID=SRV0000374\&IN_OFFICE_ID=UNT0003207> (Version current at August 19, 2005).

11. Ontario Case Costing Initiative. ICD-9 codes - requested report, 2001/2002.

12. Ninth International Classification of Diseases. Geneva: World Health Organization, 1978.

13. Ontario Ministry of Health and Long-Term Care. Ontario Drug Benefit Formulary/Comparative Drug Index, 38th edn. $<$ http://www.health.gov.on.ca/english/providers/program/drugs/ edition_38.html> (Version current at May 3, 2005).

14. Canadian Institute for Health Information. Number of Emergency Visits by Triage Level Report. National Ambulatory Care Reporting System, 2001/2002.

15. Public Health Agency of Canada. Respiratory Disease in Canada, September 2001. <http://www.phac-aspc.gc.ca/publicat/rdc$\mathrm{mrc01} / \mathrm{pdf} / \mathrm{rdc} 0901 \mathrm{e} . \mathrm{pdf}>$ (Version current at May 3, 2005).

16. Anthonisen NR. Asthma "control". Can Respir J 2004;11:529-30. 


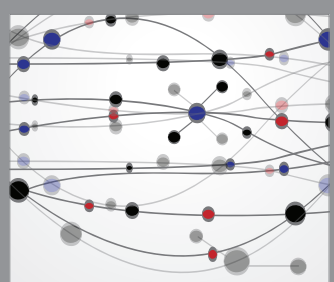

The Scientific World Journal
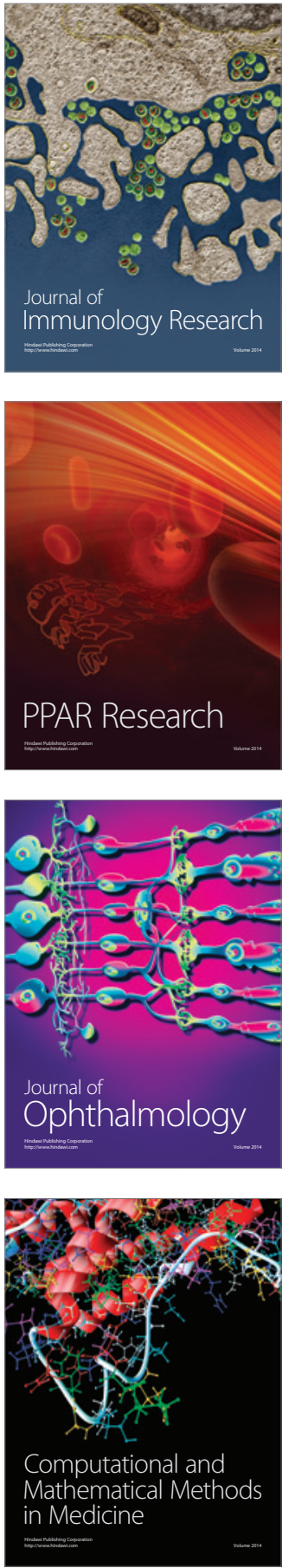

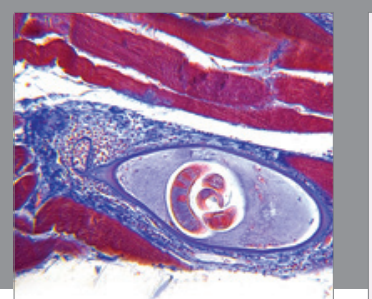

Gastroenterology Research and Practice

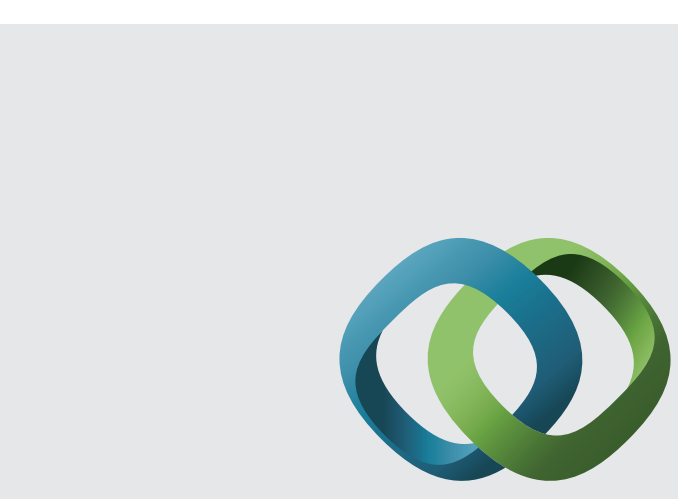

\section{Hindawi}

Submit your manuscripts at

http://www.hindawi.com
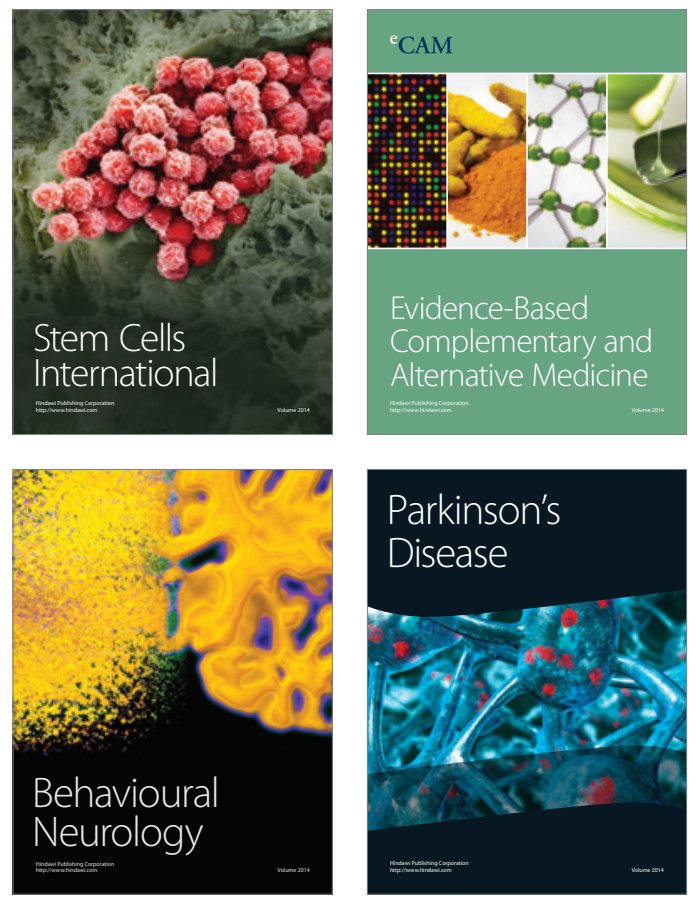
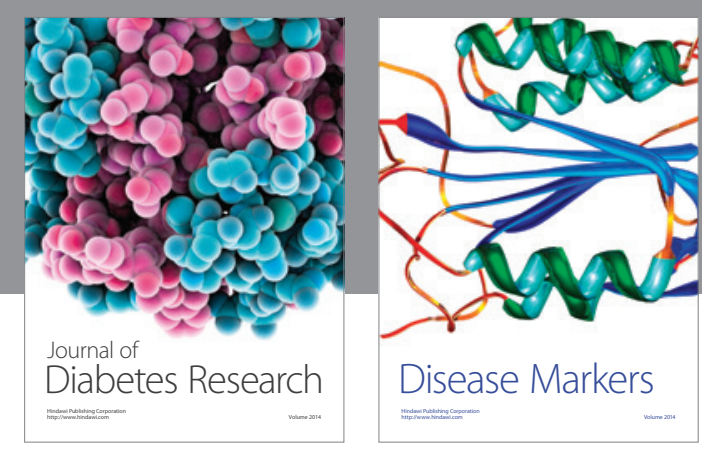

Disease Markers
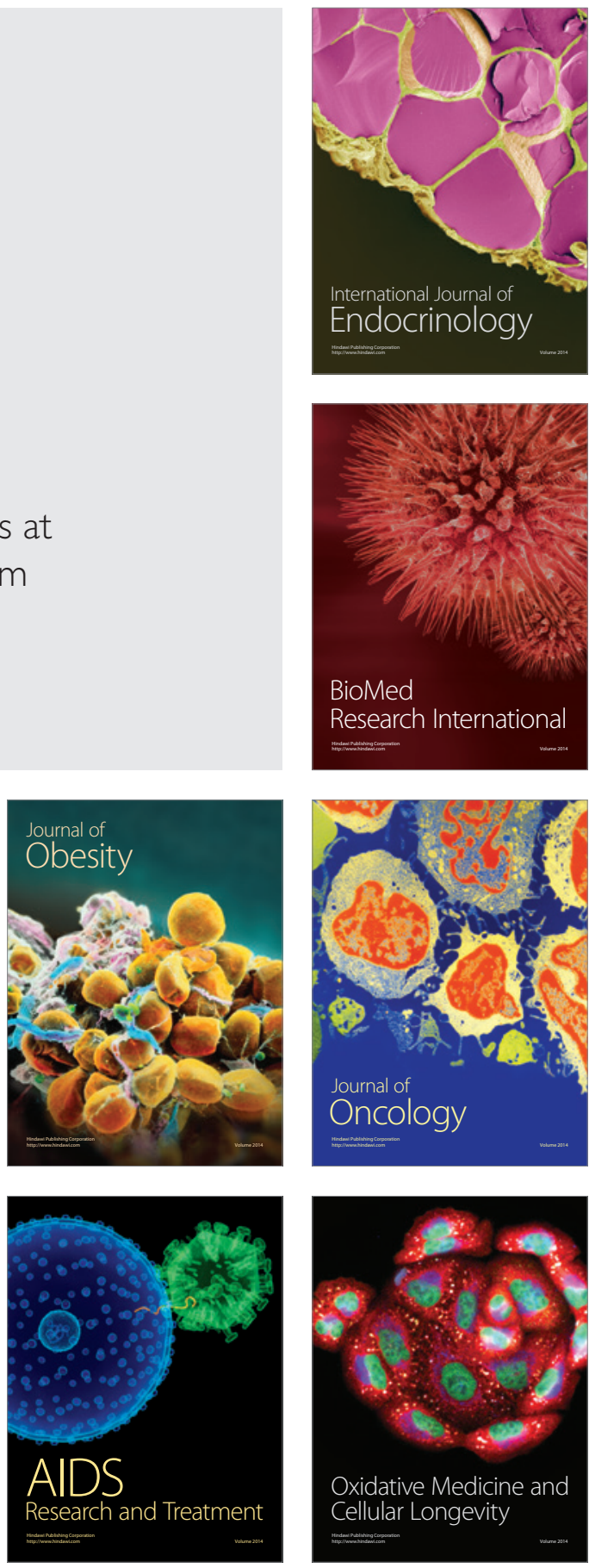